Nigerian Journal of Technology (NIJOTECH)

Vol. 35, No. 2, April 2016, pp. 458 - 464

Copyright@ Faculty of Engineering, University of Nigeria, Nsukka,

Print ISSN: 0331-8443, Electronic ISSN: 2467-8821

www.nijotech.com

http://dx.doi.org/10.4314/njt.v35i2.30

\title{
DESIGN AND ANALYSIS OF A MULTIPOINT TEMPERATURE DATALOGGER
}

\author{
0. Ojike1,*, C. C. Mbajiorgu' ${ }^{2}$, E. Anoliefo ${ }^{3}$ and W. I. Okonkwo ${ }^{4}$

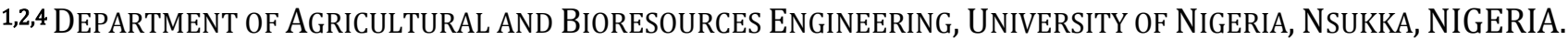 \\ 3DEPARTMENT OF ELECTRONIC ENGINEERING, UNIVERSITY OF NigERIA, NSUKKA, ENUGU STATE. NIGERIA \\ E-mail addresses: ${ }^{1}$ onyekwere.ojike@unn.edu.ng, 2 const.c.mbajiorgu@unn.edu.ng, 3 edward.anoliefo@unn.edu.ng, \\ 4ifeanyi.okonkwo@unn.edu.ng
}

\begin{abstract}
In this work, a low cost six- multipoint temperature data logger was developed. It was designed using LM35 as the sensor, and arduino Uno as the data processing element. The response time of the sensor was observed to be between three and four minutes. The comparative evaluation of the system with other established thermometers show that no two temperature meters gave the same values. However the most important thing is that all the systems recorded the same temperature flow pattern. This indicates that the systems actually senses change in the surrounding effectively. In relation to the alcohol thermometer, the designed system shows an accuracy of $+0.4^{\circ} \mathrm{C}$ at temperatures below $30^{\circ} \mathrm{C}$ and $+1.85^{\circ} \mathrm{C}$ at temperatures above $30^{\circ} \mathrm{C}$. The system gives room for effective and adjustable temperature data logging procedure. Hence, the system is recommended for use in monitoring low temperature systems.
\end{abstract}

Keywords: Temperature, Data-logger, sensor, arduino, thermometers

\section{INTRODUCTION}

Understanding of temperature flow/state during a certain time is needed in various applications. Temperature level can affect various types of measurement recorded, hence, temperature must be maintained within certain limits to achieve repeatable results, reduce the cost of tedious corrections and meet regulatory and correctness requirements [1]. With the desired temperature requirements in every field especially in agricultural productions, it is becoming more and more important for measuring and controlling of the temperature [2]. This leads to the problem of finding suitable measurement devices with the least hassles in obtaining temperature data considering that most measurements are carried out for long periods to cater for changing thermal pattern over different times/seasons. Most low-cost temperature measurement devices are hand-held and unsuitable for such work while the sophisticated ones are quite expensive [3].

Multipoint data logging is a method of automatic data capture (using digital technologies, such as advanced microprocessors, solid state sensors and fully featured software, which maximize accuracy) in which values from a sensor are recorded and stored at regular intervals [2]. Thus, a temperature data logger is a portable measurement device that is capable of autonomously recording temperature over a given time. It works with sensors to convert physical phenomena (in this case temperature) and stimuli into electronic signals such as voltage or current [4]. These electronic signals are then converted into digital data can be retrieved, and used as the need arises. As there is no moving part to wear out and with powerful software compensation, data loggers can deliver greater accuracy over larger periods of time [1].

The objectives of the work are to develop a low-cost multipoint temperature logger using LM35 and carry out a performance evaluation to compare its accuracy with already existing thermometers. The need for this design arose as a result of the fact that most multipoint temperature loggers are beyond the reach of most researchers in developing countries due to high cost of 
these systems and difficulty in assessing fund prevalent in these regions.

\section{MATERIALS AND METHODS}

The materials used for the design and their prices are as shown in Table 1. The two most important parts of the system are the sensing elements and the data processing elements.

\subsection{Sensing Element LM35}

Various temperature sensor technologies exist. As shown in Table 2, each technology sensor has its relative weak and strong points. The selection of a particular sensor for a design depends on which of these sensors (Table 2) fits into the design criteria/objective based on the sensor's weak and strong points.

Table 1: Bill of Engineering Measurement and Evaluation for the Design.

\begin{tabular}{|c|c|c|c|c|c|}
\hline $\mathrm{S} / \mathrm{n}$ & Description of item & Quantity & Unit price (n) & Total cost (n) & Re-mark \\
\hline 1 & Arduino Uno & 1 & $5,500.00$ & $5,500.00$ & \\
\hline 2 & Sparkfun microSD shield & 1 & $2,500.00$ & $2,500.00$ & \\
\hline 3 & LCD 16 & 2 & 400.00 & 800.00 & \\
\hline 4 & LM35 & 6 & 300.00 & $1,800.00$ & \\
\hline 5 & MicroSD (2GB) & 1 & $1,500.00$ & $1,500.00$ & \\
\hline 6 & Battery $12 \mathrm{~V}$ & 1 & $1,800.00$ & $1,800.00$ & \\
\hline 7 & LM7805 & 1 & 50.00 & 50.00 & \\
\hline 8 & LM317 & 1 & 50.00 & 50.00 & \\
\hline 9 & 104 Capacitors & 4 & 20.00 & 80.00 & \\
\hline 10 & Reset buttons & 6 & 20.00 & 120.00 & \\
\hline 11 & Soldering Board & 3 & 360.00 & 360.00 & \\
\hline 12 & Rainbow flex wires & $1 \mathrm{~m}$ & 500.00 & 500.00 & \\
\hline 13 & Arduino connection wire & $1 \mathrm{~m}$ & 1000.00 & 1000.00 & \\
\hline \multirow[t]{2}{*}{14} & Adaptable box & 1 & 500.00 & 500.00 & \\
\hline & TOTAL & & & $16,560.00$ & \\
\hline
\end{tabular}

Table 2: Characteristics of different types of Temperature Sensors

\begin{tabular}{|c|c|c|c|c|}
\hline & NTC Thermistor & Platium RTD & Thermocouple & Semiconductor \\
\hline Sensor & $\begin{array}{l}\text { Ceramic (metaoxide } \\
\text { spinel) }\end{array}$ & $\begin{array}{l}\text { Platinum wire-wound } \\
\text { or metal film }\end{array}$ & Thermoelectric & Semicoductor junction \\
\hline $\begin{array}{l}\text { Temperature Range } \\
\text { (typical) }\end{array}$ & -100 to $+325^{\circ} \mathrm{C}$ & -200 to $+650^{\circ} \mathrm{C}$ & -200 to $+1750^{\circ} \mathrm{C}$ & -70 to $150^{\circ} \mathrm{C}$ \\
\hline Accuracy (typical) & 0.05 to $1.5^{\circ} \mathrm{C}$ & 0.1 to $1.0^{\circ} \mathrm{C}$ & 0.5 to $5.0^{\circ} \mathrm{C}$ & 0.5 to $5.0^{\circ} \mathrm{C}$ \\
\hline Long-term Stability @ & $0.2^{\circ} \mathrm{C} /$ year (epoxy) & $0.05 \mathrm{oC} /$ year (film) & Variable, some types & \\
\hline $100^{\circ} \mathrm{C}$ & $0.02^{\circ} \mathrm{C} /$ year (glass) & $0.002 \mathrm{oC} /$ year (wire) & very prone to aging & $>10 \mathrm{c} /$ year \\
\hline Output & $\begin{array}{l}\text { NTC Resistance - } \\
4.4 \% /{ }^{\circ} \mathrm{C} \text { typical }\end{array}$ & $\begin{array}{l}\text { PTC resistance } \\
0.00385 \Omega / \Omega /{ }^{\circ} \mathrm{C}\end{array}$ & $\begin{array}{l}\text { Thermovoltage } 10 \mu \mathrm{V} \\
\text { to } 40 \mu \mathrm{V} /{ }^{\circ} \mathrm{C}\end{array}$ & $\begin{array}{l}\text { Digital, various } \\
\text { outputs }\end{array}$ \\
\hline Linearity & Exponential & Fairly linear & Most types non-linear & Linear \\
\hline Power Required & $\begin{array}{l}\text { Constant voltage or } \\
\text { current }\end{array}$ & $\begin{array}{l}\text { Constant voltage or } \\
\text { current }\end{array}$ & Self-powered & 4 to $30 \mathrm{VDC}$ \\
\hline Response Time & $\begin{array}{l}\text { Fast } 0.12 \text { to } 10 \\
\text { seconds }\end{array}$ & $\begin{array}{l}\text { Generally slow } 1 \text { to } 50 \\
\text { seconds }\end{array}$ & $\begin{array}{l}\text { Fast } 0.10 \text { to } 10 \\
\text { seconds }\end{array}$ & Slow 5 to 50 seconds \\
\hline $\begin{array}{l}\text { Susceptibility to } \\
\text { Electrical Noise }\end{array}$ & $\begin{array}{l}\text { Rarely susceptible } \\
\text { High resistance only }\end{array}$ & Rarely susceptible & $\begin{array}{l}\text { Susceptible/Cold } \\
\text { junction } \\
\text { compensation }\end{array}$ & $\begin{array}{l}\text { Board layout } \\
\text { dependent }\end{array}$ \\
\hline $\begin{array}{l}\text { Lead Resistance } \\
\text { Effects }\end{array}$ & $\begin{array}{l}\text { Low resistance parts } \\
\text { only }\end{array}$ & $\begin{array}{l}\text { Very susceptible. } 3 \text { or } \\
\text { 4-wire configurations } \\
\text { required }\end{array}$ & $\begin{array}{l}\text { None over short runs. } \\
\text { TC extension cables } \\
\text { required. }\end{array}$ & $\mathrm{N} / \mathrm{A}$ \\
\hline Cost & Low to moderate & $\begin{array}{l}\text { Wire-wound-High } \\
\text { Film-Low }\end{array}$ & Low & Moderate \\
\hline
\end{tabular}

Source [5] 
LM 35, a semiconductor temperature sensor, is chosen for this project. It has an output voltage that is proportional to the Celsius temperature. The scale factor is $0.01 \mathrm{~V} /{ }^{\circ} \mathrm{C}$. It does not require any external calibration or trimming and maintains an accuracy of $+/-0.4^{\circ} \mathrm{C}$ at room temperature and $+/-0.8{ }^{\circ} \mathrm{C}$ over a range of $0{ }^{\circ} \mathrm{C}$ to $+100{ }^{\circ} \mathrm{C}[6,7]$. Some of the advantages of using LM35 sensor are that, it can measure temperatures more accurately than thermistors and the LM 35 can generate output voltages higher than that of thermocouples and generally does not require amplification of the output voltage, It uses very little power and does not heat up [8, 9]. Its thermal response is however slow.

\subsection{Data Processing Element- Arduino}

The data processing element used in this work is arduino, a microcontroller. A microcontroller is a small computer on a single integrated circuit containing a processor, memory, and programmable input/output peripherals [10]. The arduino microcontroller is the heart of the system. The arduino UNO is a microcontroller board based on the ATmega328P. It has 14 digital input/output pins (of which 6 can be used as Pulse-width modulation, PWM outputs), 6 analog inputs, a $16 \mathrm{MHz}$ quartz crystal, a Universal Serial Bus (USB) connection, a power jack, an In-Circuit Serial
Programming (ICSP) header and a reset button. It contains everything needed to support the microcontroller; simply connect it to a computer with a USB cable or power it with a AC-to-DC adapter or battery to get started [11]. It is programmed with the Arduino Software.

\subsection{Evaluation Methods}

In order to develop this paper, a standard circuit was built around LM35 (Fig. 1). The transducer was then used to measure step increases in a given environment. An alcohol thermometer was used as a control. In order to obtain step increases in temperature a standard oven and a solar dryer were used. The thermal response time (defined as the speed at which it responds to a heat source, when a change in temperature takes place) of the system was measured by setting the oven at predetermined temperatures, the designed system sensors were put into the oven immediately the oven temperature indicator light shows that it has reached the set temperature. Then the sensors were timed and monitored to know when it will recognize the accurate oven temperature. After this, the sensors were brought out and then equally timed to know when they will normalize with the ambient temperature. The built multipoint temperature logger is shown in Fig. 2.

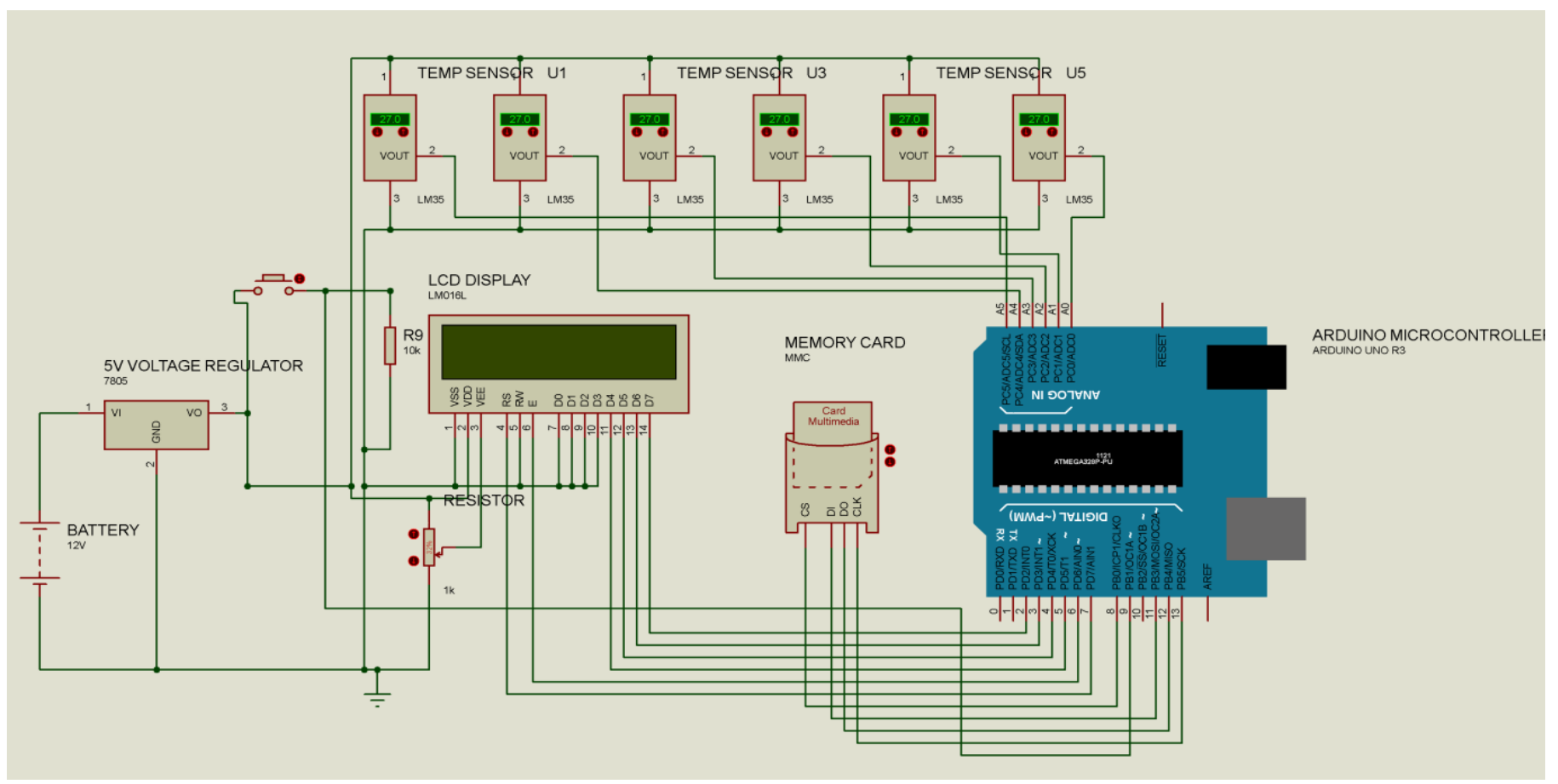

Fig.1. The Electronic Circuit Diagram of the Multi-Point Temperature Data Logger 


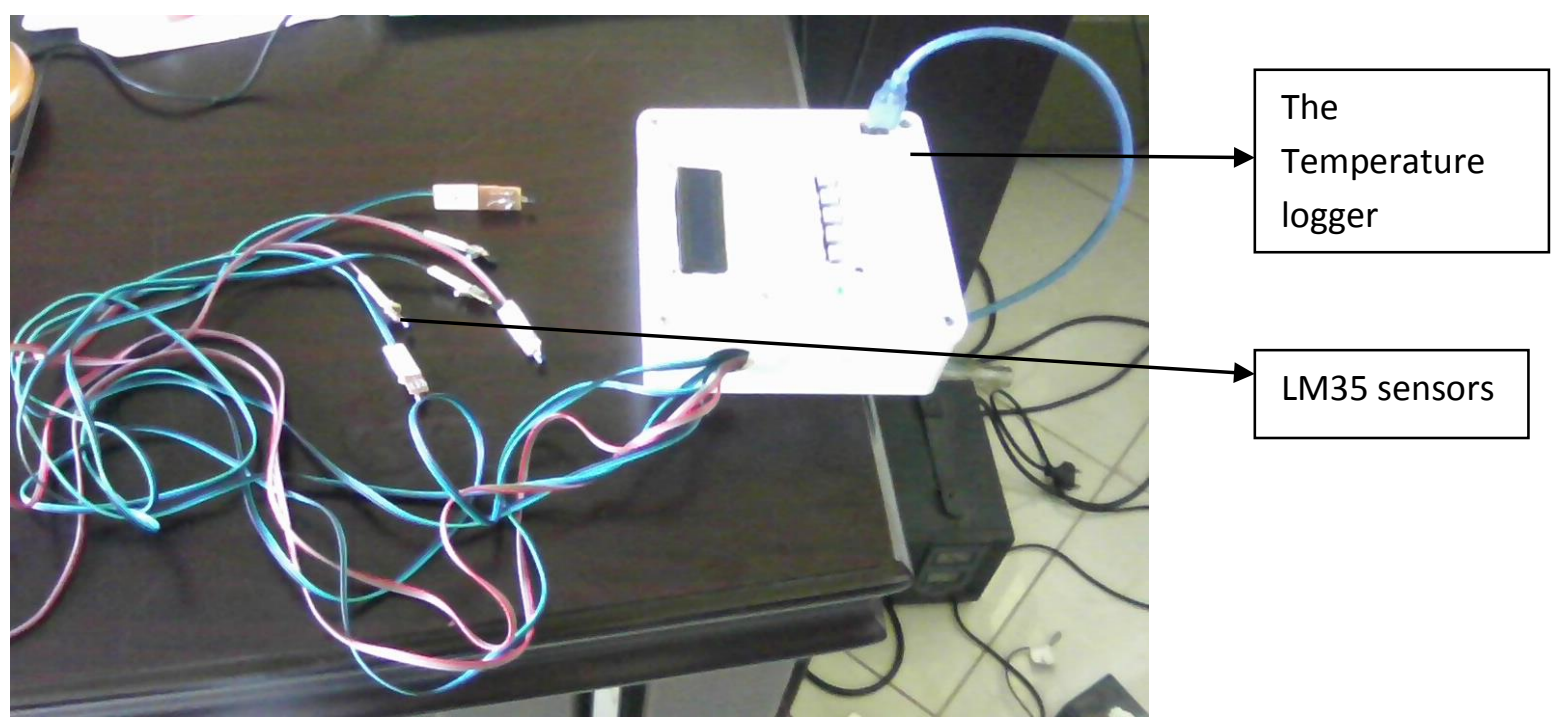

Fig. 2 Photo view of constructed Multipoint Digital Temperature Logger

\section{RESULTS AND DISCUSSION}

\subsection{Data Storage and Retrieval}

Fig 3 shows the format of temperature reading compilation in the memory card retrieved after a typical monitoring period. Column 1 represents the time periods, in this case the serial numbers actually represents interval of 30 secs. At every 30 secs. a new temperature is measured, recorded and stored in the memory card. The 30 secs time interval is a not constant, the interval can actually be adjusted if there is a need for it and it is done in the arduino software window. The rest of the columns show the temperature readings of each of the LM35 sensors used at every given time interval.

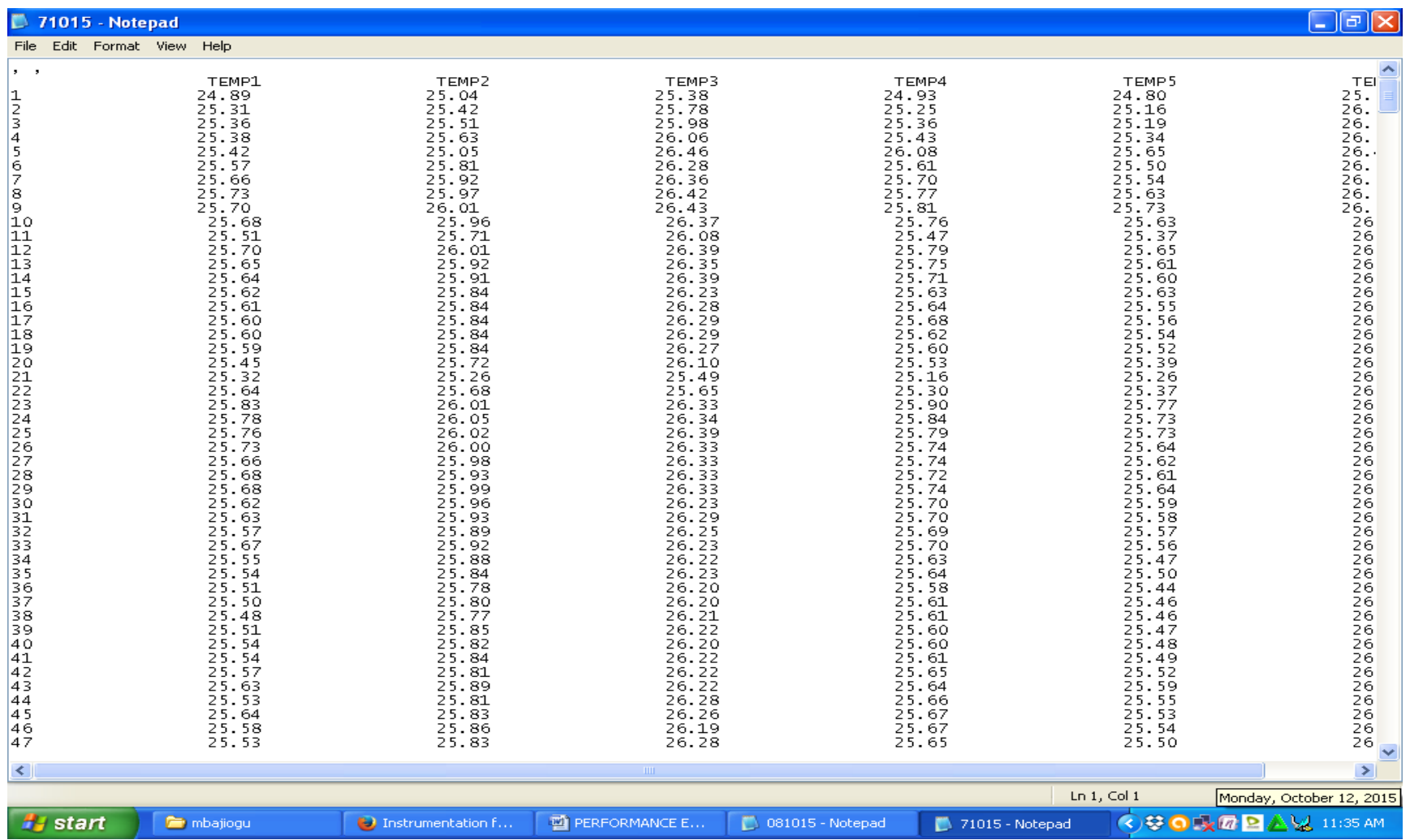

Fig. 3. Format of Data in the Memory Card. 


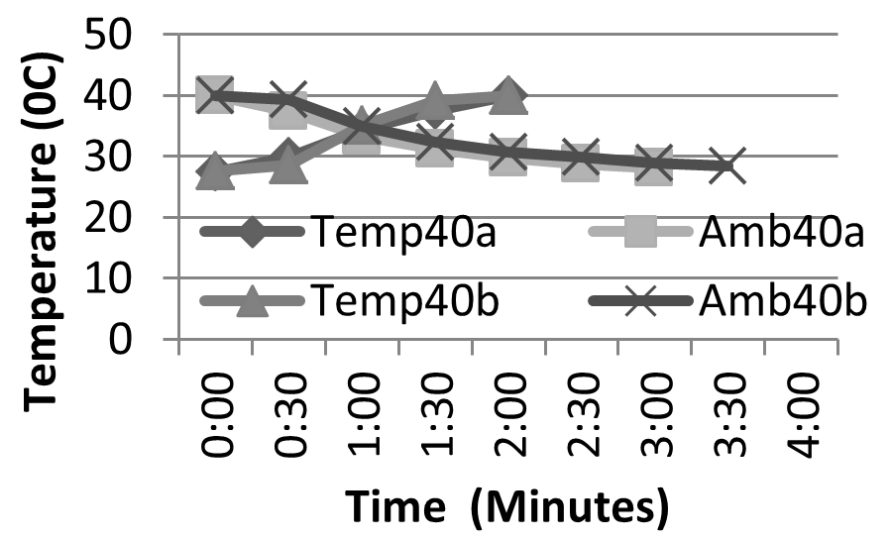

Figure 4: The response time of $L M 35$ between ambient and $40^{\circ} \mathrm{C}$

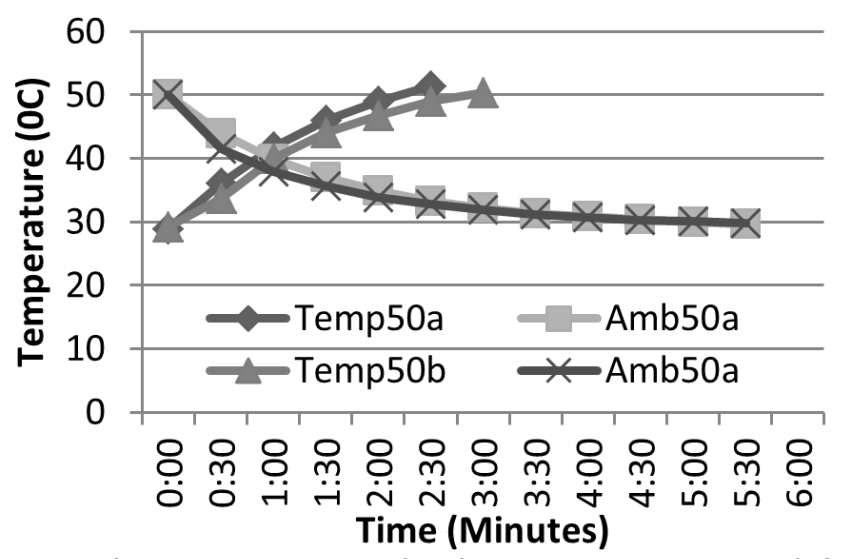

Figure 6: The response time of LM35 between ambient and $50^{\circ} \mathrm{C}$

\subsection{Sensor Response Time}

Figs. 4,5 and 6 shows the thermal response time of Lm35 as observed at three different temperatures $\left(40^{\circ} \mathrm{C}, 45^{\circ} \mathrm{C}\right.$ and $\left.50^{\circ} \mathrm{C}\right)$ of the oven replicated twice (a and b). As shown in the graph, 'Temp' (as in Temp40) line indicates how long it takes the sensor to sense the oven temperature while 'Amb' indicates how long it takes to recognize the actual ambient temperature when removed from the oven. It could be observed that in all cases it takes the sensor shorter time to recognize higher temperature than to return back to ambient temperature when removed from the oven. It was equally observed that the response times over different temperature ranges are not the same but increases as the difference between the temperatures increases. For example the response time between ambient temperature and $40^{\circ} \mathrm{C}$ was observed to be approximately Two minutes while from ambient to $45^{\circ} \mathrm{C}$ is Two and half minutes. In all cases the response time of a complete circle (i. e. rising to the oven temperature and returning to the ambient temperature) is between 3 -4 minutes. This is in agreement with literature [12]. In

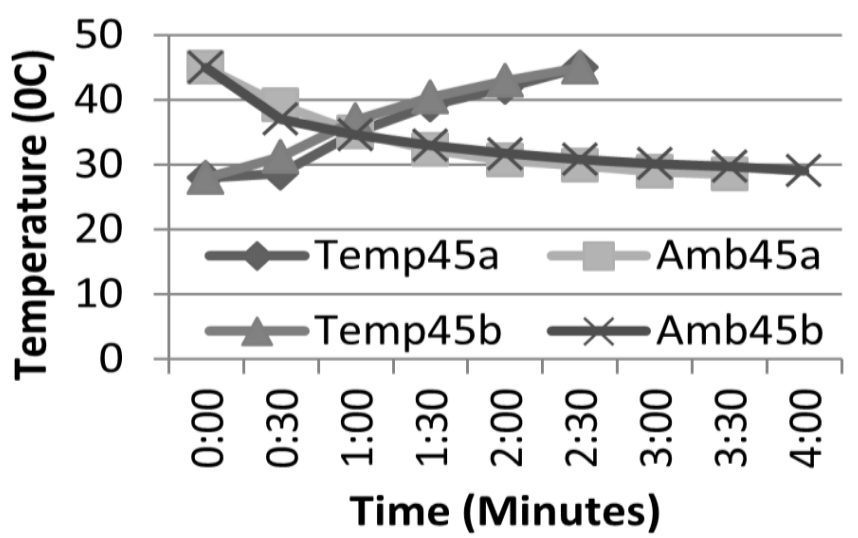

Figure 5: The response time of $L M 35$ between ambient and $45^{\circ} \mathrm{C}$

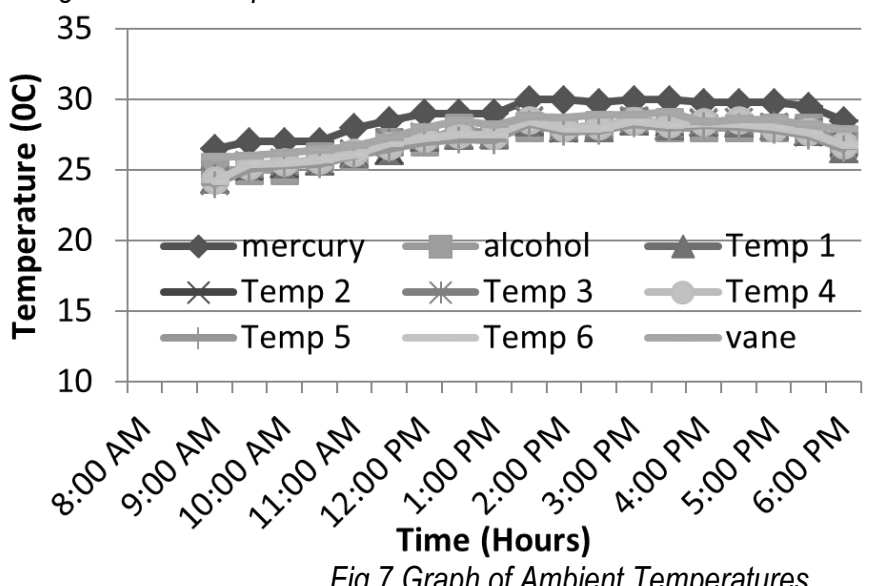

Fig.7 Graph of Ambient Temperatures

spite of this, LM 35 can still be effectively used especially in situations where temperature measurements can safely be measured at intervals of about three minutes.

\subsection{Comparative Evaluation with Other Thermometers}

Fig. 7 shows a graphical relationship between Mercury thermometer, Alcohol thermometer, Digital meter (vane) and the different sensors of the designed multi point temperature data logger at ambient conditions. It could easily be seen that no two temperature meters recorded the same value. Equally, the designed system varies in line with the established thermometers. In all cases, the mercury thermometer recorded the highest values followed by the digital meter. The temperatures of the alcohol thermometer and the designed system were interwoven at most points. Using the alcohol thermometer reading as the mean temperature, a cumulative standard deviation of $0.4^{\circ} \mathrm{C}$ was calculated for the designed system. This is in line with literature [6, 7] that LM35 maintains an accuracy of $+/-0.4^{\circ} \mathrm{C}$ at room temperature. 
Fig. 8 shows the temperature variations in a solar dryer as recorded by the six sensors of the designed system and the alcohol thermometer while the mercury thermometer records the ambient temperature. As can be seen, the designed system sensors temperature reading varies in sympathy with the thermometer reading throughout the duration of the study. Unlike in Fig. 7 where the designed system recorded values lower than the thermometer reading, Fig. 8 shows intermingling of the different sensors with the thermometer reading with no clear demarcation between them. Divakar has argued that at temperatures between $30^{\circ} \mathrm{C}$ and $60^{\circ} \mathrm{C}$ that LM35 system showed more accuracy in sensing temperatures than at temperature below $30^{\circ} \mathrm{C}$ [8]. Using the thermometer reading as the mean temperature, a cumulative standard deviation of $1.85^{\circ} \mathrm{C}$ was calculated for the designed system. This is in line with the conclusions of $[13,8]$ who all observed accuracy of $+2^{\circ} \mathrm{C}$ in their work.

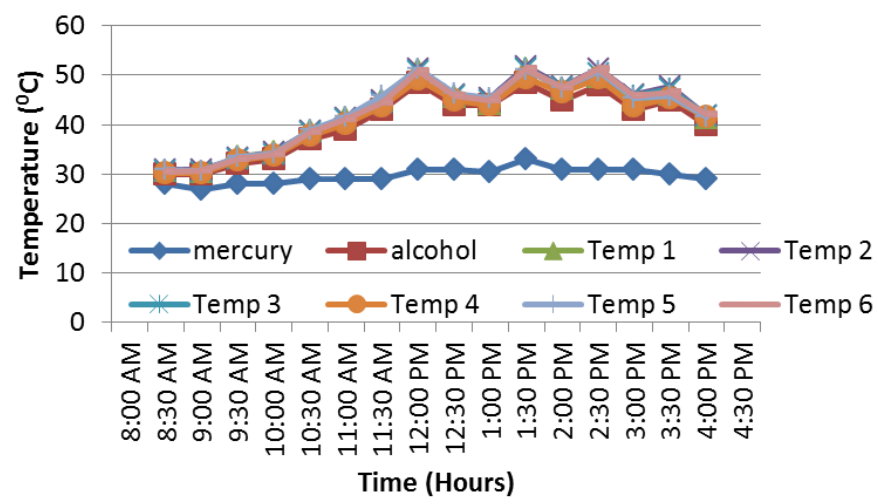

Fig. 8 Graph of Solar Dryer Temperature Gradient

\subsection{Cost Evaluation}

A major objective of any engineering design is to produce systems that will be affordable to the target market and yet durable. To this end, every effort was made to use cheaply available but durable materials. The total cost of the system was Sixteen Thousand Five Hundred and Sixty naira (N16, 560.00) an equivalent of 82.50 U.S. dollars. The breakdown of this cost is already shown in Table 1. This amount in relation to similar systems is relatively cheap. As observed in OMEGA, OneStop Source for Process Measurement \& Control, an 8 Input Portable Thermometer/Data Logger with SD card is valued at between 1,999.00 and 2550.00 U.S. dollars [14].

\section{CONCLUSION}

In this paper, a multi-point temperature data logger was designed using LM35 as the sensors. It was observed that no two temperature meters gave the same values. However the most important thing is that all the systems recorded the same temperature flow pattern. This indicates that the systems actually senses change in the surrounding effectively. In relation to the alcohol thermometer, the designed system shows an accuracy of $+0.4^{\circ} \mathrm{C}$ at temperatures below $30^{\circ} \mathrm{C}$ and $+1.85^{\circ} \mathrm{C}$ at temperatures above $30^{\circ} \mathrm{C}$. The system gives room for effective and adjustable temperature data logging procedure.

Hence, the system is recommended for use in monitoring low temperature systems, that is, systems whose temperatures are in the range of $-55^{\circ} \mathrm{C}$ to $+150^{\circ} \mathrm{C}$.

\section{REFERENCES}

[1] Sagarkumar S. Badhiye, S. S., Chatur, P. N. and Wakode, B. V. "Data Logger System: A Survey", Intl. Journal of Computer Technology and Electronics Engineering, 2008, pp 24-26.

[2] Abrar, M. D. and Patil, R. R. "Multipoint Temperature Data Logger and Display on PC through Zigbee using PSoC", International Journal of Advanced Research in Computer and Communication Engineering,Vol. 2, Issue 9, 2013,pp 3382 - 3391

[3] Sharan, R. V. "Development of a Remote Automatic Weather Station with a PC-based Data Logger", International Journal of Hybrid Information Technology, Vol.7, Number 1, 2014, pp.233-240.

[4] Waghmare, M. B. and Chatur, P. N. "Temperature and Humidity Analysis using Data Logger of Data Acquisition System: An Approach", Intl. Journal of Emerging Technology and Advanced Engineering, Vol. 2, Number 1, 2012, pp 102-106.

[5] Temperature Product group. "Temperature Sensors: Advantages and Disadvantages" http://measspec.com.cn/downloads/Temperature Sensor Advan tages.pdf, Accessed on October 15, 2015.

[6] Vinod, S., Raja, M. and Sailaja, D. "Air Pollution Check in Vehicles by Using GSM and GPS", Intl Journal of Professional Engineering Studies, Vol. 5, Number 3, 2015, pp 14-17.

[7] Shelar, M., Singh, J. and Tiwari, M. "Wireless Patient Health Monitoring System", Intl Journal of Computer Applications, Vol. 62, Number 6, 2013, pp 1-5. 
[8] Divakar, V. "Design and Implementation of Microcontroller Based Temperature Data Logging System", Intl. Journal of Engineering and Advanced Technology, Vol. 3, Issue 2, 2013, pp 129-135.

[9] Vandana, W., Madiwale, G. and Awasthi, N. "An Efficient Data Logger System for Continous Monitoring And Traceability of Cargo: Application of GPS and GSM Technology", Intl. Journal of Research in Engineering and Technology, Vol. 3, Number 6, 2014, pp 569- 572.

[10] Aneja, B. and Singh, S. "Review of Temperature Measurement and Control", Intl. Journal of Electrical and Electronics Engineers, Vol. 3, Number 2, 2011, pp 29- 37.

[11] Arduino cc. "Arduino and Genuino Products Overview"
https://www.arduino.cc/en/Main/ArduinoBoardUno , Accessed on October 15, 2015.

[12] Texas Instruments, "LM35 Precision Centigrade Temperature http://www.ti.com/lit/ds/symlink/lm35.pdf, Accessed on August 15, 2015.

[13] Kumar, S. R. and Rameshkumar, S. "Industrial Temperature Monitoring and Control System through Ethernet Lan", IJECS, Vol. 2, Number 6, 2013, pp 1988-1991.

[14] OMEGA Engineering inc. "8 Input Portable Thermometer/Data Logger with SD card" www.omega.com/disclaimers/copyright.html, Accessed on August 15, 2015. 